\title{
ANALYSIS OF THE SURVIVAL OF PATIENTS WITH BREAST CANCER DEPENDING ON AGE, MOLECULAR SUBTYPE OF TUMOR AND METABOLIC SYNDROME
}

\author{
S.M. Grybach 1, 2, *, L.Z. Polishchuk', V.F. Chekhun ${ }^{1}$ \\ ${ }^{1}$ R.E. Kavetsky Institute of Experimental Pathology, Oncology and Radiobiology \\ NAS of Ukraine, Kyiv 03022, Ukraine \\ ${ }^{2}$ Kyiv Regional Oncology Dispensary, Kyiv 04107, Ukraine
}

\begin{abstract}
Aim: To analyze the survival of patients with breast cancer (BC) depending on age, molecular subtype of the tumor and the presence of metabolic syndrome. Patients and Methods: We have analyzed the results of examination and treatment of 202 patients with BC of stages I-III. The patients were distributed by age into 2 groups. The group 1 included 86 elderly patients (from 65 to 84 years old), the group $2-116$ younger patients (from 32 to 64 years). An overall 1-, 3- and 5-year survival rates of the treated patients were assessed. The significance of factors influencing the overall survival (OS) of patients with $\mathrm{BC}$ was determined using the methods of statistical analysis. Results: Molecular subtype of BC significantly affects survival rates: in a case of a luminal B subtype the 5-year OS was $71.6 \%$ vs $80 \%(p<0.05)$ in groups 1 and 2 , respectively while in a case of a basal-like subtype it was $60.2 \%$ and $71.6 \%(p<0.05)$. The presence of metabolic syndrome significantly reduced the 5-year OS (up to $70.7 \%$ and $80.6 \%$, $p<0.05$ in groups 1 and 2, respectively). Conclusion: The OS is lower in elderly patients with BC compared with younger patients, especially in those who suffer from metabolic syndrome.
\end{abstract}

Key Words: breast cancer, elderly age, metabolic syndrome, receptor status, 1-, 3-, 5-year overall survival.

Breast cancer $(\mathrm{BC})$ occupies the first place in the structure of cancer-related morbidity and mortality in women in Ukraine, as well as in countries of Europe and America. The number of new cases in the world exceeds 1 million per year. The statistical data show that in the economically developed countries there is a stable increase in the incidence and mortality caused by BC. Over the past 30 years the number of $B C$ cases has increased by more than $20 \%$, and mortality by $11 \%$ [1].

In Ukraine, according to the National Cancer Registry, in 2016 the incidence of BC and mortality from this disease amounted respectively 64.6 and 29.3 cases per 100 thousand female population. The highest incidence of $B C$ is observed in the age range of 65-69 years -170.3 cases per 100 thousand population, whereas in the next 10 years (age range 70-79 years) the number of patients with $\mathrm{BC}$ decreases yielding 88.3 cases per 100 thousand people [2].

According to the classification of the World Health Organization (2012), there are the following age ranges: young age (25-44 years), middle age (45-59 years), elderly age (60-75 years), old age (76-90 years)) and long-livers (more than 90 years) [3]. Exactly in elderly and old women there are disturbances in the fat and carbohydrate balance, cardiovascular diseases (hypercholesterolemia, hypertension, type II diabetes, insulin resistance, etc.), which may precede the onset of $\mathrm{BC}$. According to the

Submitted: February 14, 2018.

*Correspondence: E-mail: sergadoc1975@ukr.net Abbreviations used: $\mathrm{BC}$ - breast cancer; ER - estrogen receptor; MS - metabolic syndrome; OS - overall survival; PR - progesterone receptor. literature data $[4,5]$, the metabolic syndrome (MS) is an integral indicator of concomitant disease in patients with BC. This syndrome includes a complex of disorders of carbohydrate and fat metabolism that manifest itself by central obesity, diabetes mellitus, lipid metabolism disorders, arterial hypertension. The MS suppresses immunological reactivity, antitumor resistance, and induces an additional comorbidity, including cardiovascular and renal pathology. In view of the above, the MS can also affect the overall survival (OS) rate in patients with BC.

The aim of this study was to conduct a comparative analysis of the 1-5-year OS rate of patients with locally advanced BC in the groups of elderly and younger patients, depending on the clinical-morphological and immunohistochemical features of the tumors and the presence of MS.

\section{MATERIALS AND METHODS}

In the study, we have analyzed the results of complex clinical examination and treatment of 202 patients with BC of I-III stages treated at the Kyiv Regional Cancer Dispensary (KRCD) in 2009-2015. The stage of the tumor process was established according to the TNM classification ( $7^{\text {th }}$ edition). All patients underwent laboratory, clinical and radiological examinations; an analysis of the histological structure of the removed tumors, the expression of molecular biological markers (hormonal receptors (estrogen receptor (ER), progesterone receptor (PR), epidermal growth factor receptor HER2/neu) for the establishment of the molecular BC subtype according to approved protocols for examination in patients with BC.

On the basis of the results of treatment and clinical monitoring of the patients, the 1-, 3-, and 5-year OS of patients depending on the age of patients, tumor 
size, metastasis in lymph nodes, molecular subtypes of tumors, and the presence of MS were analyzed. Complex treatment was performed for all patients: surgical treatment - radical mastectomy according to Madden, adjuvant radiotherapy for lymphatic outflow routes (median focal dose of irradiation was $46 \mathrm{~Gy}$ ) and adjuvant polychemotherapy ( 6 courses according to the CAF scheme: endoxan $600 \mathrm{mg} / \mathrm{m}^{2}, 5$-fluorouracil $600 \mathrm{mg} / \mathrm{m}^{2}$, doxorubicin $60 \mathrm{mg} / \mathrm{m}^{2}$ ). The treatment of patients was carried out in accordance with the local standards for treatment of patients with $\mathrm{BC}$, provided in the KRCD in 2009-2015, guided by the methodological recommendations of the National Cancer Institute in 2008-2015. Patients who did not receive full treatment due to poor performance status were not included in our study. All patients provided informed written consent for participation in the research and the use of their personal data for scientific purposes.

An assessment of the 1-, 5-year OS of the treated patients and determination of the factors that affect this index were carried out using statistical methods for survival analysis. The comparison of the obtained data was carried out using the Cox test and Wilcoxon - Gehan method. For statistical analysis of the data, Microsoft Excel and STATISTICA 9 for Windows XP were used. The differences between the groups were considered to be significant at $p<0.05$.

\section{RESULTS AND DISCUSSION}

The survey involved 202 patients with BC, including a significantly higher number of patients with stage II $(n=152)$ and stage III $(n=36)$ than stage I $(n=14)$. All patients were distributed by age into 2 groups. The group 1 included 86 patients (42.6\%) with the age from 65 to 84 years, and the group 2 included 116 patients $(57.4 \%)$ with the age from 32 to 64 years. We have chosen such age groups because it is known that the risk of $\mathrm{BC}$ development is 150 times higher for women older than 65 years compared with those younger than 30 [6]. To study the factors that affect the OS of elderly patients, we conducted an analysis of OS, depending on a number of clinical, molecular-biological characteristics of tumors and the presence of concomitant pathology. In particular, in these age groups we have analyzed the following important parameters which affect the survival rates: 1 ) the size of the primary tumor and regional lymph metastasis; 2) molecular subtype of the tumors; and 3) the impact of MS.

The effect of the size of the primary tumor and regional lymph metastasis on the survival rates of the patients with $B C$. The size of the primary tumor and metastasis in regional lymph nodes are the most important factors for the prognosis of the disease course [7]. Metastases in 4 or more regional lymph nodes significantly increase the risk of distant metastasis [8]. An analysis of the size of the tumors and metastatic lesions in regional lymph nodes showed the following: in group 1 the average diameter of the tumors was $2.86 \pm 0.67 \mathrm{~cm}$, in group $2-2.71 \pm 0.71 \mathrm{~cm}$, that is, there was no significant difference. The size of tumors up to $2.2 \mathrm{~cm}$ in diam- eter was noted in 2 (2.3\%) patients from group 1 and in $6(5.1 \%)$ patients from group 2 . The diameter of the tumors from 2 to $5 \mathrm{~cm}$ was detected in $35(40.7 \%)$ and $59(50.9 \%)$ patients of the groups 1 and 2 , respectively, more than $5 \mathrm{~cm}$ in diameter - in $49(57.1 \%)$ of patients from group 1 and 51 (44\%) of the patients from group 2 (Table 1).

Table 1. Clinical and biological features of tumors in patients from group 1 and group 2

\begin{tabular}{lcc}
\hline \multicolumn{1}{c}{ Parameters } & $\begin{array}{c}\text { Group 1 } \\
65-78 \text { years } \\
\text { old, } \mathrm{n} / \%\end{array}$ & $\begin{array}{c}\text { Group 2 } \\
\text { 32-64 years } \\
\text { old, } \mathrm{n} / \%\end{array}$ \\
& $\begin{array}{c}\mathrm{n}=86 / 100 \%) \\
(\mathrm{n}=116 / 100 \%)\end{array}$ \\
\hline Mean age, years & $70.6 \pm 6.7$ & $47.3 \pm 9.2$ \\
\hline Mean tumor size, cm & $2.86 \pm 0.67$ & $2.71 \pm 0.71$ \\
$<2$ & $2 / 2.3^{*}$ & $6 / 5.1$ \\
$2-5$ & $35 / 40.7$ & $59 / 50.9$ \\
$>5$ & $49 / 57.0^{*}$ & $51 / 44.0$ \\
\hline Metastases to regional lymph nodes & & \\
are absent & $27 / 31.4$ & $48 / 41.4$ \\
\hline Frequency of lymph nodes metasta- & & \\
ses, total: & $59 / 68.6$ & $68 / 58.6$ \\
1-4 lymph nodes & $43 / 50.0$ & $57 / 49.1$ \\
5-8 lymph nodes & $16 / 18.6^{*}$ & $11 / 9.5$ \\
\hline Molecular subtype of BC: & & \\
luminal A & $39 / 45.3^{*}$ & $45 / 38.8$ \\
luminal B & $32 / 37.2$ & $41 / 35.3$ \\
basal-like & $15 / 17.5^{\star}$ & $30 / 25.9$ \\
\hline
\end{tabular}

Note: *The difference between the groups is significant, $p<0.05$.

In patients from group 1 , the incidence of lymph node metastases was higher than in group 2 (68.6\% vs $58.6 \%)$ with a greater number of affected lymph nodes (5-8), the frequency of which was $18.6 \%$ vs $9.5 \%$.

In the analysis of OS of patients from groups 1 and 2 depending on the size of the tumors, we established the following: with tumor size $<5 \mathrm{~cm}$, the OS of patients from both groups was equal (100\%), the 3 -year OS in patients from group 1 compared with group 2 was $80.1 \%$ vs $88.7 \%$, and the 5 -year OS in elderly patients was $73.4 \%$, whereas in group 2 it amounted to $84.1 \%$.

It was found that in patients from group 1, the OS rates were lower than in group 2. In particular, the 1 - and 5-year OS of patients from group 1 compared with group 2 were $93.3 \%$ vs $95.1 \%$ ( $p>0.05)$; and $57.3 \%$ vs $70.0 \%(p<0.05)$, respectively.

A comparative analysis of the survival depending on metastasis in regional lymph nodes (Fig. 1) showed that in elderly and young patients without lymph node involvement, the 1-year OS was high $(95.5 \%$ and $100 \%$, respectively). The 3 -year OS under the same conditions in patients from group 1 was $88.9 \%$, in patients from group 2 it was higher and amounted to $95.6 \%$. The 5-year OS in elderly patients was significantly lower than in young patients ( $81.3 \%$ vs $88.5 \%)$.

With a metastatic lesions in 1-4 regional lymph nodes, the 1-year OS was lower than in patients without metastases in the lymph nodes, and was $91.2 \%$ and $96 \%$ in the groups 1 and 2 , respectively, whereas the 3 -year OS of patients from groups 1 and 2 was $77.8 \%$ and $88.4 \%$, respectively, and the 5 -year OS in these groups was $68.6 \%$ vs $79.3 \%$ (Table 2). So, OS in elderly patients with tumors $<5 \mathrm{~cm}$ and with metastases in 1-4 lymph nodes was significantly lower than in young patients. 


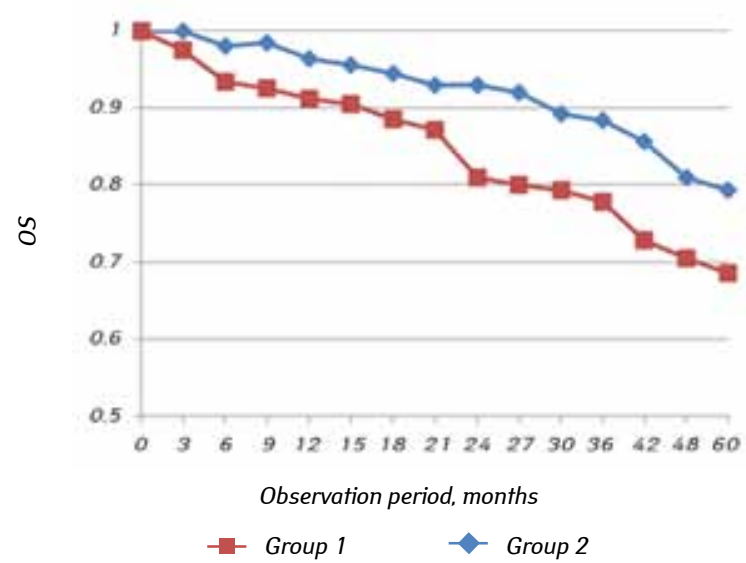

Fig. 1. The curves of the 1-, 3- and 5-year OS of patients from groups 1 and 2 with metastases in 1-4 lymph nodes; Kaplan Mayer curve ( $p=0.005$ by Cox criterion)

Table 2. OS of the elderly patients (group $1, \geqslant 65$ years) and younger patients (group 2, <65 years) depending on the clinical characteristics of the tumor process

\begin{tabular}{|c|c|c|c|c|}
\hline \multirow{2}{*}{\multicolumn{2}{|c|}{$\begin{array}{l}\text { Clinical characteristics of the tumor process } \\
\text { and the number of patients in the groups }\end{array}$}} & \multicolumn{3}{|c|}{$0 \mathrm{~S}, \%$} \\
\hline & & 1-year & 3-year & 5 -year \\
\hline Tumor size $2-5 \mathrm{~cm}$ & $\begin{array}{l}\text { Group 1 }(n=35) \\
\text { Group 2 }(n=59)\end{array}$ & $\frac{100.0}{100.0}$ & $\begin{array}{l}80.1 \\
88.7\end{array}$ & $\begin{array}{l}73.4 \\
84.1^{*}\end{array}$ \\
\hline $\begin{array}{l}\text { Regional lymph node metas- } \\
\text { tases are absent }\end{array}$ & $\begin{array}{l}\text { Group 1 }(n=27) \\
\text { Group } 2(n=48)\end{array}$ & $\begin{array}{c}95.5 \\
100.0\end{array}$ & $\begin{array}{l}88.9 \\
95.6\end{array}$ & $\begin{array}{l}81.3 \\
88.5\end{array}$ \\
\hline $\begin{array}{l}\text { Metastases in 1-4 lymph } \\
\text { nodes }\end{array}$ & $\begin{array}{l}\text { Group } 1(n=43) \\
\text { Group } 2(n=57)\end{array}$ & $\begin{array}{l}91.2 \\
96.0\end{array}$ & $\begin{array}{ll}77.8 \\
88.4\end{array}$ & $\begin{array}{c}68.6 \\
79.3^{*}\end{array}$ \\
\hline
\end{tabular}

Relation between survival rates and molecular subtype of BC. Clinical and morphological characteristics of the tumor are not sufficiently precise to predict the course and prognosis of the disease, therefore, the molecular characteristics of tumors, i.e. expression of molecular biological markers in tumor cells, is of high importance [9]. Differences in the expression levels of certain markers could help to explain why the tumors with similar prevalence and histological structure differ in aggression and the disease course. According to the molecular genetic classification, all malignant tumors of the mammary gland by their biological characteristics are classified into the following subtypes: luminal $A$, luminal $B$, and triple-negative or basal-like $\mathrm{BC}[10,11]$.

Analysis of the expression of hormonal receptors (ER and PR) and Her-2/neu in BC cells showed that luminal $A$ subtype predominated in the patients from group 1 (39/45.3\%), but not in group 2 (45/38.8\%) $(p<0.05)$. Luminal B subtype was detected in almost the same number of patients from the groups 1 and 2 (32 (37.2\%) patients and $41(35.3 \%)$ patients, respectively). Basal-like subtype of $\mathrm{BC}$ in group 1 was determined less frequently than in group 2 ( $15(17.5 \%)$ patients and 30 (25.9\%) patients, respectively).

We have analyzed the 1-, 3-, 5-year OS rates in elderly with different molecular genetic types of BC (Table 3, Fig. 2). The 1-year OS rate in patients with luminal and young patients type A tumors of groups 1 and 2 was almost identical ( $97.1 \%$ and $97.7 \%$, respectively), while the 3- and 5-year OS of patients from group 1 were lower than in patients from group $2(81.2 \%$ vs $90.7 \%$, and
$78.4 \%$ vs $82.4 \%$, respectively). The 1 -year OS of patients with luminal B subtype from groups 1 and 2 was also nearly identical and amounted to $92.1 \%$ and $94.6 \%$, respectively. The 3 -year OS of patients from group 1 was $84.1 \%$, in patients from group $2-88.6 \%$. The 5 -year OS of elderly patients was $71.6 \%$, and young patients $80 \%$. The 1-year OS in patients with basal-type BC from groups 1 and 2 was $87.5 \%$ and $90.2 \%$, respectively. The 3 -year OS of patients from group 1 was $77.4 \%$, patients from group $2-86.1 \%$. The 5 -year OS in elderly patients was $60.2 \%$, and in young patients $-71.6 \%$.

Table 3. OS rate in elderly (group 1) and younger (group 2) patients with $\mathrm{BC}$ of different molecular subtypes

\begin{tabular}{lcccc}
\hline \multirow{2}{*}{ Molecular subtype } & Groups and num- & \multicolumn{3}{c}{ 0S, \% } \\
\cline { 3 - 5 } & ber of patients & 1-year & 3-year & 5-year \\
\hline Luminal A & Group 1 $(\mathrm{n}=39)$ & 97.1 & 81.2 & 78.4 \\
\cline { 2 - 5 } & Group 2 $(\mathrm{n}=45)$ & 97.7 & 90.7 & 82.4 \\
\hline Luminal B & Group 1 $(\mathrm{n}=32)$ & 92.1 & 84.1 & 71.6 \\
\cline { 2 - 5 } & Group 2 $(\mathrm{n}=41)$ & 94.6 & 88.6 & $80.0^{\star}$ \\
\hline Basal-like & Group 1 $(\mathrm{n}=15)$ & 87.5 & 77.4 & 60.2 \\
\cline { 2 - 5 } & Group 2 $(\mathrm{n}=30)$ & 90.2 & 86.1 & $71.6^{*}$ \\
\hline
\end{tabular}

Note: ${ }^{\star}$ The difference between the groups 1 and 2 is significant, $p<0.05$.

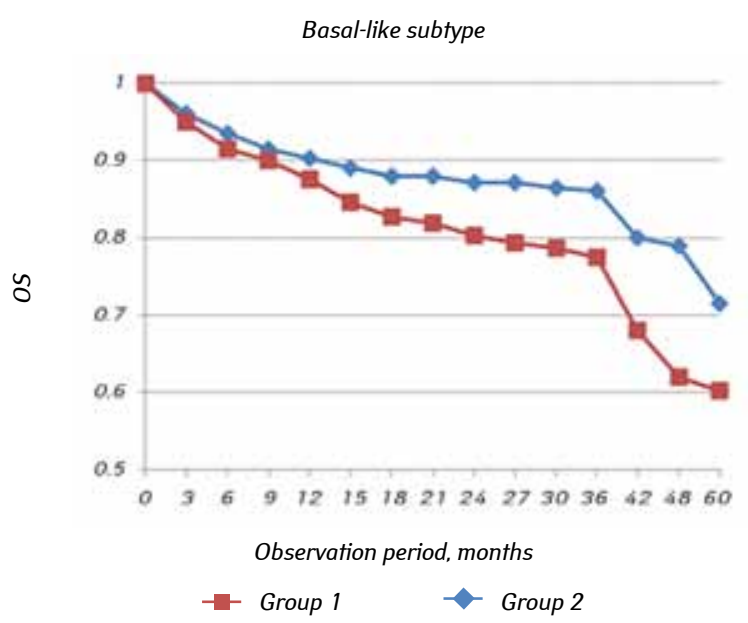

Fig. 2. The curves of the 1-, 3- and 5-year OS of patients from groups 1 and 2 with basal-like subtype; Kaplan - Mayer curve ( $p=0.005$ by Cox criterion)

Thus, the tendency towards worsening of the OS rates was found in all molecular BC subtypes, but significantly lower OS rates were observed in elderly patients with luminal $B$ and basal-like molecular $\mathrm{BC}$ subtypes compared to young patients. Our data are in agreement with the data of other authors on the unfavorable course of the tumor process in the case of luminal B and the basal-like BC subtypes [12].

The impact of MS in survival rates of $B C$ patients. We have analyzed the clinical and biological features of BC in elderly and young patients depending on the presence or absence of MS. In the group 1 of patients MS was diagnosed in 46 (53.5\%) out of 86 patients, in the group 2 - in $48(41.4 \%)$ out of 116 patients. The main characteristics of the tumor process in patients with MS are given in Table 4. The patients with MS, compared with patients without MS, were older, had lower number of tumors $<2 \mathrm{~cm}$ and higher number of tumors $>5 \mathrm{~cm}$, a higher rate of lymph nodes metastasis $(24.0 \%$ vs $14.6 \%)$, a higher frequency of luminal B subtype (47.8\% vs $41.7 \%$ ). 
Table 4. Clinical and biological characteristics of tumors in elderly and young adult patients with MS

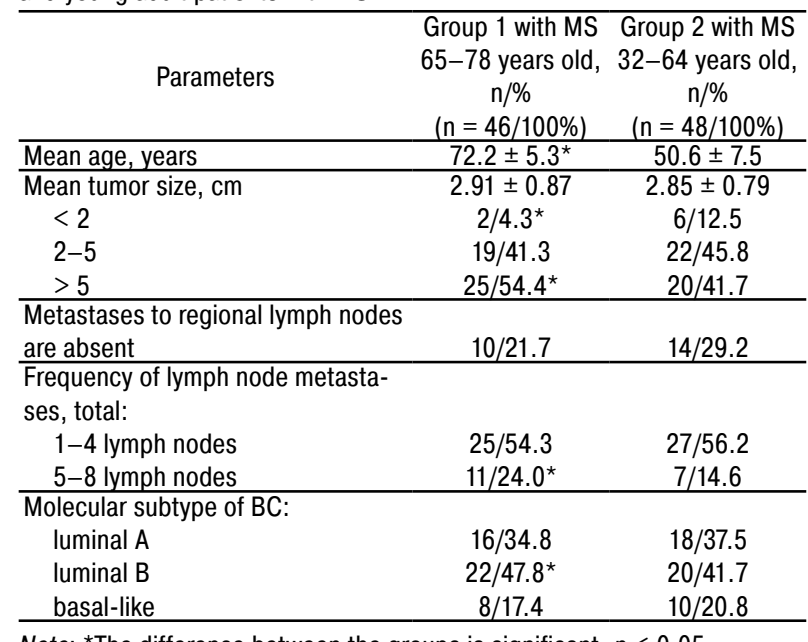

Note: ${ }^{\star}$ The difference between the groups is significant, $p<0.05$.

Next, we have analyzed the impact of MS on survival of BC patients of different age. The analysis of 1-, 3- and 5 -year OS of all BC patients (elderly and young) with and without MS (Fig. 2) has shown that the 1-year OS in patients with MS was slightly lower than in patients without MS and amounted to $92.5 \%$ and $96.8 \%$, respectively. The 3-year OS of patients with MS was $82.9 \%$, in patients without MS $-84.6 \%$, and the 5-year OS were $70.7 \%$ and $80.6 \%$, respectively (Table 5). Consequently, 1-, 3-, and 5-year OS in BC patients with MS was lower than in patients without MS, but statistically significant differences were detected regarding only 5-year survival rates, which confirms the data of other researchers $[13,14]$. So, OS in elderly and young patients with MS was significantly lower than in patients without MS. The indexes of OS in elderly and young patients with and without MS, depending on clinical and morphological and immunohistochemical characteristics of tumors are presented in Table 6.

Table 5. The OS of the elderly (group 1) and younger (group 2) patients depending on the presence $(+)$ or absence $(-)$ of the MS

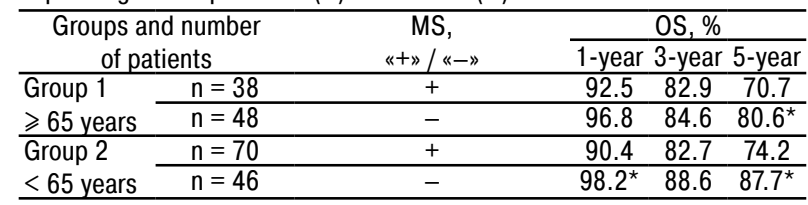

Note: ${ }^{*}$ The difference between the groups with and without MS is significant, $p<0.05$.

Table 6. The OS of the elderly (group 1) and young (group 2) patients with or without MS depending on molecular BC subtype

\begin{tabular}{|c|c|c|c|c|}
\hline \multirow{2}{*}{ Molecular BC subtype } & \multirow{2}{*}{ Groups of patients } & \multicolumn{3}{|c|}{$\mathrm{OS}, \%$} \\
\hline & & 1-year & 3 -year & 5-year \\
\hline \multirow[t]{4}{*}{$\overline{\text { Luminal } \mathrm{A}}$} & Group 1, MS + & 95.2 & $80.2^{*}$ & $75.5^{\star}$ \\
\hline & Group 1, MS - & 98.3 & 87.4 & 85.8 \\
\hline & Group 2, MS + & 96.7 & 90.2 & $80.3^{\star \star}$ \\
\hline & Group 2, MS - & 98.8 & 94.1 & 84.7 \\
\hline \multirow[t]{4}{*}{ Luminal B } & Group 1, MS + & $94.8^{*}$ & $78.3^{\star}$ & $72.5^{\star \star}$ \\
\hline & Group 1, MS - & 100 & 86.2 & 80.2 \\
\hline & Group 2, MS + & $90.4^{*}$ & 83.6 & $78.4^{\star \star}$ \\
\hline & Group 2, MS - & 100 & 88.9 & 86.7 \\
\hline \multirow[t]{4}{*}{ Basal-like } & Group 1, MS + & 92.7 & $76.5^{\star}$ & $68.1^{\star \star}$ \\
\hline & Group 1, MS - & 95.1 & 84.3 & 77.4 \\
\hline & Group 2, MS + & 89 * & $77.2^{\star}$ & $70.6^{\star \star}$ \\
\hline & Group 2, MS - & 97.1 & 87.8 & 72.1 \\
\hline
\end{tabular}

Notes: *The difference between the subgroups with and without MS of group 1 is significant, $p<0.05$. ${ }^{* \star}$ The difference between the subgroups with and without MS of group 2 is significant, $p<0.05$.
The analysis of OS in elderly patients with and without MS depending on the size of the tumors showed the following (Table 7): if tumors were $<5 \mathrm{~cm}$, the 1 -year OS of elderly patients with MS was $95 \%$, without MS $-100 \%$. The 3-year OS of patients from group 1 with MS was $77.1 \%$, in patients without MS - 83.4\%. The 5-year OS in BC patients with and without MS was $68.4 \%$, in young patients $-76.5 \%$. In young patients with and without MS, and with tumors < $5 \mathrm{~cm}$ were as follows: 1 -year OS $-97.4 \%$ and $100 \%$; 3 -year OS $-80.9 \%$ and $91.7 \%$; 5 -year OS $-79.5 \%$ and $84.9 \%$, respectively. The OS rate in the elderly patients without metastasis in lymph nodes and with and without MS was as follows: 1 -year OS of patients with MS - 95.5\% and without MS 97.3\%; 3-year OS of patients with MS was $85.1 \%$, patients without MS - 93.4\%; the 5-year OS was $79.2 \%$ and $84.3 \%$, respectively. In young patients with and without MS, in the absence of affected lymph nodes OS values were as follows: 1-year OS - 96.7\% and $100 \%$; 3 -year OS - $92.5 \%$ and $95.6 \%$; 5 -year OS $-90.1 \%$ and $92.7 \%$, respectively. In elderly patients with metastases in 1-4 lymph nodes with MS without MS, the 1-year OS rate was $92.4 \%$ and $100 \%$; the 3 -year OS $-70.5 \%$ and $80.9 \%$; and the 5 -year OS in patients $60.6 \%$ and $72.2 \%$, respectively. OS of young patients with metastases in 1-4 lymph nodes with and without MS was as follows: the 1 -year OS $95,6 \%$ and $100 \%$; the 3 -year OS $80.3 \%$ and $93.8 \%$; and the 5 -year OS $71.5 \%$ and $86.4 \%$, respectively.

Based on comparisons of OS values in elderly and young patients with MS and without MS, it can be concluded that MS affects the course of the disease, reducing OS, especially in older women with a more widespread tumor process, especially in women with metastases in 1-4 lymph nodes. However, the effect of MS on OS most significantly increased after 36 months of observation. Thus, our data are in accordance with the data of many authors [7, 10, 14, 15], concerning the negative impact of concomitant pathology on the course and prognosis of the tumor process.

To study the effect of MS on the OS rates, the indexes of OS in elderly and young patients with different

Table 7. The OS of the elderly (group 1) and young (group 2) patients with $(+)$ or without (-) MS depending on clinical characteristics of tumor process

\begin{tabular}{|c|c|c|c|c|}
\hline \multirow{2}{*}{\multicolumn{2}{|c|}{$\begin{array}{l}\text { Clinical characteristics of the tumor process } \\
\text { and groups of patients }\end{array}$}} & \multicolumn{3}{|c|}{ OS, $\%$} \\
\hline & & 1-year & 3-year & 5-year \\
\hline \multirow[t]{4}{*}{ Tumor size $<5 \mathrm{~cm}$} & Group 1, MS + & $95^{\star}$ & 77.1 & $68.4^{*}$ \\
\hline & Group 1, MS - & 100 & 83.4 & 76.5 \\
\hline & Group 2, MS + & 97.4 & 80.9 & $79.5^{\star \star}$ \\
\hline & Group 2, MS - & 100 & 91.7 & 84.9 \\
\hline \multirow{4}{*}{$\begin{array}{l}\text { Regional lymph node } \\
\text { metastases are absent }\end{array}$} & Group 1, MS + & 95.5 & 85.1 & $79.2^{\star}$ \\
\hline & Group 1, MS - & 97.3 & 93.4 & 84.3 \\
\hline & Group 2, MS + & 96.7 & $92.5^{\star \star}$ & 90.1 \\
\hline & Group 2, MS - & 100 & 95.6 & 92.7 \\
\hline \multirow{4}{*}{$\begin{array}{l}\text { Metastases } \\
\text { in } 1-4 \text { regional lymph } \\
\text { nodes }\end{array}$} & Group 1, MS + & $92.4^{\star}$ & $70.5^{\star}$ & $60.6^{\star}$ \\
\hline & Group 1, MS - & 100 & 80.9 & 72.2 \\
\hline & Group 2, MS + & $95.6^{\star}$ & $80.3^{\star \star}$ & $71.5^{\star \star}$ \\
\hline & Group 2, MS - & 100 & 93.8 & 86.4 \\
\hline
\end{tabular}

Note: *The difference between the subgroups with and without MS of group 1 is significant, $p<0.05 .{ }^{* *}$ The difference between the subgroups with and without MS of group 2 is significant, $p<0.05$. 
molecular subtypes of tumors in patients with MS and without MS were analyzed (Table 6, Fig. 3). The 1-year OS of elderly patients with luminal A subtype with and without MS was $95.2 \%$ and $98.3 \%$, the 3 - and 5 -year OS were $80.2 \%$ and $87.4 \%$; and $75.5 \%$ and $85.8 \%$, respectively. The 1 -year OS of elderly patients with luminal B subtype with MS and without MS was $94.8 \%$ and $100 \%$, the 3 -year OS $-78.3 \%$ and $86.2 \%$, and the 5 -year OS $-72.5 \%$ and $80.2 \%$, respectively (Fig. 3). The 1-year OS of elderly patients with basal-like subtype with MS and without MS was $92.7 \%$ and $95.1 \%$, the 3 -year OS $-76.5 \%$ and $84.3 \%$, and the 5 -year OS $-68.1 \%$ and $77.4 \%$, respectively (Fig. 4 ).

The 1-year OS of young patients with luminal A subtype with MS and without MS was $96.7 \%$ and $98.8 \%$, the 3 -year OS $-90.2 \%$ and $94.1 \%$, the 5-year OS $-80.3 \%$ and $84.7 \%$, respectively.

The 1-year OS in young patients with luminal B subtype with MS and without MS was $90.4 \%$ and $100 \%$, the 3-year OS - $83.6 \%$ and $88.9 \%$, the 5 -year OS $78.4 \%$ and $86.7 \%$, respectively. The 1 -year OS rate in young patients with basal-like subtype with MS and without MS was $89 \%$ and $97.1 \%$, the 3 -year OS $77.2 \%$ and $87.8 \%$, the 5 -year OS $-70.6 \%$ and $72.1 \%$.

The comparison of OS values in the groups allows conclude that the worst OS rate was observed in the elderly patients with basal-like BC subtype, which is in accordance with the opinion of many authors regarding the unfavorable prognosis of basal-type tumors [16] and the unfavorable effects of concomitant pathology on the course of the tumor process.

It's evident that elderly patients more often suffer from different concomitant pathologies [17]. In particular, in elderly patients with BC, there are prevalent the diseases of the organs of the cardiovascular and musculoskeletal systems, carbohydrate metabolism disorders, liver and gallbladder pathologies, while in the anamnesis of young patients more often are documented benign tumors and dyshormonal hyperplasia of the mammary glands, and ovarian cysts [18]. That's why lower OS in elderly patients with BC could be explained by the use of less intensive methods of local treatment, a decreased number of polycheLuminal B subtype

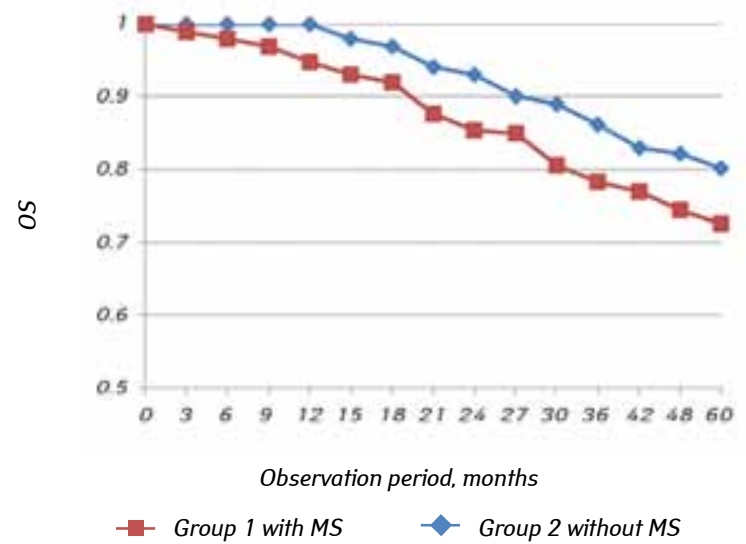

Fig. 3. The curves of the 1-, 3- and 5-year OS of patients from groups 1 and 2 with or without MS and luminal B subtype; Kaplan - Mayer curve ( $p=0.005$ by Cox criterion)

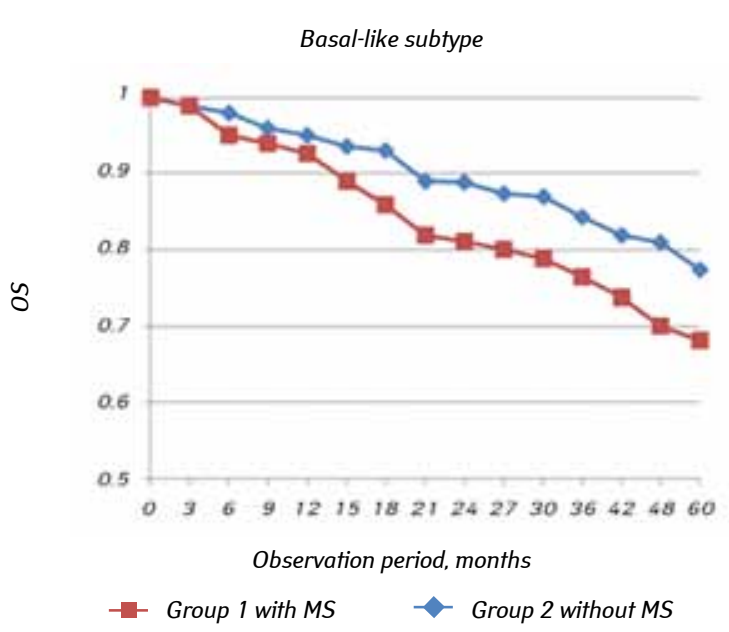

Fig. 4. The curves of the 1-, 3- and 5-year OS of patients from groups 1 and 2 with or without MS and basal-like subtype; Kaplan - Mayer curve ( $p=0.005$ by Cox criterion)

motherapy cycles and a reduction in the dosage of anticancer drugs, since in this group of patients the concomitant pathology interferes with therapeutic interventions [19]. However, in our study, all patients with $\mathrm{BC}$ received a comprehensive treatment at standard doses, because the patients with concomitant pathology which contraindicated for complex treatment, were not included in our study.

\section{CONCLUSION}

In conclusion, in elderly patients with $\mathrm{BC}$ we have revealed a statistically significant difference in the 1-, 3- and 5-year OS rates compared to young patients, namely, in patients with tumor sizes up to $5 \mathrm{~cm}$, with metastatic lesions in 1-4 lymph nodes, and with luminal B and basal-like BC subtypes. The OS rates were significantly lower in patients with MS compared to the patients without MS, especially in elderly patients.

\section{REFERENCES}

1. http: breast-cancer.org.ua.

2. National Cancer Register of Ukraine. Kyiv 2016; www.ucr.gs.com.ua.

3. http: who.int/topics/classification.

4. Chen X, Lu W, Zheng W, et al. Obesity and weight change in relation to breast cancer survival. Breast Cancer Res Treat 2010; 10: 1007-8.

5. Nikitin YuP, Openko TG, Simonova GI. Metabolic syndrome and its components as possible modifiable risk factors for cancer (literary review). Sib Oncol J 2012; 2: 6872 (in Russian).

6. Imyanitov EN, Khanson KP. Molecular Oncology: Clinical Aspects. St-Petersburg: ID SPMABO, 2007: 212 (in Russian).

7. Bondar GV, Skochilyas TL, Sedakov IE. Prognostic markers, hormonal and medicinal sensitivity of breast cancer. Zaporiz Med J 2002; 5: 58-61 (in Ukrainian).

8. Diab SG, Elledge RM, Clark GM. Tumor characteristics and clinical outcome of elderly women with breast cancer. J Natl Cancer Inst 2000; 92: 550-6.

9. Acevedo F, Camus M, Vial C, et al. Predictive value of conventional immuno-histochemical biomarkers in breast cancer. Rev Med Chil 2015; 143: 724-32.

10. Kwast AG, Voogd AC, Menke-Pluijmers ME, et al. Prognostic factors for survival in metastatic breast cancer 
by hormone receptor status. Breast Cancer Res Treat 2014; 145: 503-11.

11. Paluch-Shimon $S$, Catane $R$, Ben-Baruch $N$, et al. Breast cancer with HER2/neu over-expression - are we dealing with a heterogeneous disease? Eur J Cancer 2006; 4: 164-7.

12. Pappo I, Karni T, Sandbank J, et al. Breast cancer in the elderly: histological, hormonal and surgical characteristics. Oncologist 2011; 16: 61-70.

13. Liedtke C, Thill M. Committee on behalf of the $\mathrm{AB}$ AGO recommendations for the diagnosis and treatment of patients with early breast cancer: update 2016. Breast Care 2016; 11: 204-14.

14. Shchepotin IB, Zotov OS, Lyubota RV, Lyubota II. Clinical and laboratory indices of insulin resistance syndrome as a predictor of the course of breast cancer. Sci Vistnik Nat Med Univ 2009; 2: 168-73 (in Ukrainian).
15. Hardefeldt PJ, Penninkilampi R, Edirimanne S, Eslick GD. Physical activity and weight loss reduce the risk of breast cancer: a meta-analysis of 139 prospective and retrospective studies. Clin Breast Cancer 2017; 4: 174-9.

16. Elmorani $F$, Zine $M$, Afif $M$, et al. Management of early breast cancer in older women: from screening to treatment. Breast Cancer 2015; 7: 165-71.

17. Bily OM, Vinnikov VA, Krasnoselsky MV, et al. Prospects for the use of molecular biological markers for localized breast cancer. Review. Ukr Radiol J 2016; 24: 13-8 (in Ukrainian).

18. Parmar V, Badwe RA, Hawaldar R, et al. Predictors of recurrence after breast conservation treatment in 1668 women. The Breast 2005; 14: 29-30.

19. O'Connor $T$, Shinde A, Doan C, et al. Managing breast cancer in the older patient. Clin Adv Hematol Oncol 2013; 11: 341-7. 